Vol. 19(2010): 269-283.

\title{
Understanding the diversification and specialization of farm businesses
}

\author{
Helena Hansson*, Richard Ferguson and Christer Olofsson \\ Department of Economics, Swedish University of Agricultural Sciences, PO Box 7013, SE-75007 Uppsala, Sweden \\ *e-mail: Helena.Hansson@ekon.slu.se
}

\begin{abstract}
This paper addresses the development of farm businesses in Sweden, 2000-2007, with regard to their specialization in single farm enterprises, diversified agricultural production and diversification with new income-generating ventures. Furthermore, regression analysis is used to study the impact of farm characteristics on the observed specialization and diversification. The study is based a panel data set of about 900 farms participating in the Swedish Agricultural Economics Survey. Results show that farms are increasingly engaging in diversified activities, though in most firms these activities make only minor contributions to total revenue. Results also show that the degrees of specialization and diversification are influenced by characteristics of firms' business structure, financial and demographic conditions. These results contribute to the understanding of farm business development, as well as show the need for policy makers and farm advisors to consider the differences between farms pursuing different development strategies in their efforts to influence behavior.
\end{abstract}

Key-words: Business structure, demographic conditions, diversification, financial conditions, specialization, Sweden

\section{Introduction}

Small firms are recognized as important engines in local economies (Davidsson et al. 1999), and the establishment of competitive rural businesses is a major goal both in the European Union Rural De- velopment Program 2007 - 2013 and in the Swedish Rural Development Program 2007 - 2013. In rural areas, small firms are often traditional farm businesses, as exemplified in Sweden, where 96 percent of rural firms have less than 10 employees, and over one quarter are commercial farm businesses (Nilsson et al. 2009, Statistics Sweden, 2008). Currently, 


\section{Hansson, H. et al. The diversification and specialization of farm businesses}

however, traditional farming is going through major structural changes in many countries, where farm businesses are facing increasing competition, new emerging markets, such as agricultural tourism and bio-energy, and increasingly volatile prices. There are clear trends of traditional farm businesses exiting agricultural production, and/or merging with other farms, resulting in fewer and larger businesses (e.g. Statistics Sweden 2002, 2006, 2008; Tauer and Mishra 2006; MacDonald et al. 2007). In this business climate, continued farm business survival may depend largely on the strategic choice of either focusing on a specialized line of production, to increase margins and/or scale, or diversifying into new ventures, to supplement business income.

In the European Union Rural Development Program, 2007-2013, the diversification of farm businesses is identified as a prioritized area. Accordingly, in the Swedish Rural Development Program, 2007 -2013, diversification of rural firms is named as one of four central goals. However, at the same time, with technological development continuing to offer ways to improve production efficiency, specialization within a single farm enterprise is another plausible development strategy for individual firms to pursue.

This raises the question of how farm businesses are developing over time. To what extent are farms specializing in single enterprises, versus diversifying business income through additional agricultural enterprises, and/or non-agricultural ventures? Furthermore, if policy and advisory services are to be effective, it would be valuable to know if there are underlying factors that influence the direction and degree of development.

Much of the more recent research on the strategic development of farm businesses has focused largely on patterns of diversification into non-agricultural activities, leaving out analysis of alternative strategies for farm business development, such as specialization in single production enterprises and/or diversification with other primary agricultural productions. A number of authors have assessed the influence of selected farm characteristics on the probability of observing certain diversification activities (e.g. McNally 2001; Chaplin et al. 2004; Barbieri and Mahoney, 2009), but at the same time, the diversified activities have been measured in a binary variable, reducing the possibility of analysis of the contributions that activities are making to businesses. Furthermore, with the notable exception of McNally (2001), little previous research on farm diversification has used panel data, limiting assessment of development patterns over time.

The focus in this study lies in tracing development patterns over time and in exploring how the characteristics of a farm business, such as business structure, financial conditions and demographic characteristics, influence strategic choices of single-venture specialization and diversification within and outside of conventional agricultural activities. With this focus, two distinct aims are addressed: First, the pattern of farm business development through specialization within single production enterprises, diversification within primary agricultural production and diversification into new income-generating ventures in Swedish farms during $2000-2007$ is described. Second, the impact of business structure, including the extent of existing diversification/specialization, farm size, number of employees, and business form; financial conditions, including liquidity, solidity, return and possibilities for internal capitalization; and demographic characteristics, including gender and age, on the extent to which farmers specialize in single agricultural ventures (specialization), diversify their activities within conventional agriculture (agricultural diversification) and/or diversify into activities outside of conventional agriculture (non-agricultural diversification) is assessed.

This study contributes to the literature by increasing the understanding of the business development process in farms in three particular ways: First, the study is not limited to investigating diversification into non-traditional agricultural production, but considers also the alternative business development strategies of specialization in single agricultural enterprise and diversification within traditional agricultural production. Second, the study investigates the impact of farm characteristics on the extent to which certain strategies are exhibited, rather than merely the occurrence of a particular strategy. Third, as the study is based on panel data, it provides an analysis of the evolution 
Vol. 19(2010): 269-283.

of development strategies over time. In addition to contributions to academic understanding, the findings in this study provide advisors and policy makers with information about the heterogeneous behavior of farm businesses that can lead to better targeted support and policy.

\section{Theoretical background}

\section{Definitions}

The concept of diversification among farm businesses has long received attention from researchers, yet there is little consensus on a single definition. Much of earlier research focused on diversification as a means of reducing risk, defining diversification as the development of multiple production ventures within the farm business unit, perhaps but not necessarily using the farm's existing resources, resulting in additional distinct marketed outputs (e.g. Johnson, 1967; Heady, 1952). This basic definition is still used in current research (e.g. Mishra et al. 2004; Sumner and Wolf, 2002), though increasingly focus is on diversification as an entrepreneurial reaction to change rather than risk management.

Much of the literature is unclear in the distinction between the farm business, the farmer, and the farm household. As Gasson et al. (1988) points out, the business, the individual, and the family are particularly intertwined in family farms, and the three levels influence one another in management decisions. In the general business literature, however, diversification refers to multiple activities within a single business enterprise (Robson et al. 1993). This definition should not be confused with the concept of pluriactivity, which refers to the activities of the farmer, and includes off-farm work as a "diversified" source of income; nor with the concept of portfolio entrepreneurship, which refers to a single entrepreneur holding multiple separate businesses (Alsos and Carter 2006, Alsos et al. 2003, Carter 1999). While these two concepts are similar with the concept of diversification in that multiple sources of revenue and possible synergy and conflict between the different ventures' resource demands, the concept of diversification differs by being exclusively focused on multiple income generating activities within a single business entity.

Another point of inconsistency in the literature concerns exactly what additional ventures to consider as diversification. In the early literature, any venture that provided additional streams of income that could balance the risks is considered diversification (Johnson 1967, Heady 1952). Thus additional ventures in conventional agricultural production, such as dairy, pork, poultry and/or crop production, are means of diversification. Much of the more recent literature, however, limit the concept of diversification to gainful activities that take place outside the primary production of food and fiber, such as contract machine services, food processing, or summer cottage rentals, and therein exclude multiple agricultural production activities as diversified ventures (e.g. Barbieri and Mahoney 2009, Turner et al. 2003, Ilbery 1991, Slee 1987).

Barbieri and Mahoney (2009) identify seven different types of diversification, including nontraditional crops, livestock, and/or practices; alternative marketing schemes; tourism and recreation; lease and rental of resources; contract machine services; value-added processing; and preservation, education and consulting services. On a more general level, Ilbery (1991) notes that diversification can be either structural, including activities oriented outward from the farm towards the public, or agricultural, including activities focused on farming and the various types of farm work (but which are different from traditional farming). Ilbery's structural diversification includes ventures such as tourism, value-adding to products and renting out of land and buildings, whereas his agricultural diversification includes ventures such as contract field work.

These examples from the literature show that while there is variation in exact definitions, different types of diversification can be identified, depending on the level of conceptualization. In the present study, the concept of diversification is differentiated at three different levels. At the most aggregate level, specialized versus differentiated sources of revenue are considered. 


\section{Hansson, H. et al. The diversification and specialization of farm businesses}

The concept of specialization has not received attention in the literature to the same extent as the concept of diversification, though the literature measuring the degree of specialization has often focused on the proportion of total farm revenue that is obtained from the main farm enterprise or from the enterprise of interest (e.g. Hansson 2007, Hadley 2006, Brümmer 2001) and this strategy is followed in this study.

At the next level, the study distinguishes between diversification within versus outside conventional agriculture. Diversification within conventional agriculture implies multiple sources of revenue from primary agricultural production for which there are established industries, such as pork or wheat. Diversification outside conventional agriculture implies revenue-generating activities based on non-conventional agricultural production in addition to one or more conventional enterprises. High specialization in one farm enterprise has repeatedly been found in empirical studies to decrease technical and/or economic efficiency, concepts intimately related to profitability (e.g. Hansson 2007, Hadley 2006, Brümmer 2001). Reasons elaborated in the literature include that high dependency on a single farm enterprise makes the farm more vulnerable to changing market conditions. Thus, firms with multiple conventional enterprises can reduce risk, just as farms with non-conventional ventures can.

Finally, a distinction is made between two types of diversification activities outside conventional agriculture: Activities based on new markets for existing farm resources are differentiated from activities based on new value-added products and services. These two alternatives reflect different expressions of dynamic capability (Eisenhardt and Martin 2000, Teece et al. 1997), where on the one hand the firm redirects existing resources in a relatively unchanged form and on the other hand modifies or creates new resources. In activities based on new markets for existing resources, such as providing contract work and renting out of farm buildings and equipment, the farm's resources are used in essentially the same way, but revenues are attained from new markets. Activities based on value-added products and services, such as food processing and agricultural tourism, involve a more innovative process, where resources are re-formed, acquired or created to build increased customer value in a new product or service.

\section{Review of related research}

Previous research on farm diversification related to this study can be divided into two general types. On the one hand there are studies that have taken a more general approach, seeking to identify patterns of diversification and/or indentifying factors associated with diversification. On the other hand there are studies investigating particular types of diversification, such as small-scale foods or agricultural tourism, where venture-specific issues come more into focus. The aim in the present study is clearly related to the first of these two types.

McNally (2001) investigated patterns of agricultural diversification over the time period 19881997 in England and Wales. The most frequently reported diversification strategy was hirework, though there was a significant increase in the occurrences of renting out of farm buildings over the studied period as well. The study also showed that the total number of diversified farms was rather stable over time and that smaller farm size, and/or a livestock based production generally lowered the likelihood of diversification. At the same time, McNally found that diversification activities based on the traditional farm resources played only a minor role in the development of business income.

In a benchmark study intended to contribute to policy development, Turner et al. (2003) reviewed and updated research on farm diversification in England during the 1990s. They reported that farm diversification increased during the studied period, with over 53 percent of the surveyed farms reporting diversified activities. They also found that lager farms have more resources to direct toward diversified activities, and that certain types of primary production on farms - grain and crop production and "mixed" production, rather than dairy, beef and sheep production - were more apt to diversify. The study found diversified activities to be relatively 
Vol. 19(2010): 269-283.

profitable, and in contrast to McNally (2001), to be a significant contribution to total farm income.

Chaplin et al. (2004) found that, in the three central European countries - Czech Republic, Hungary and Poland - the level and effect of diversification is relatively small. Relating the probability of observing a diversified farm to farm and farmer characteristics, the study found that farm and farmer characteristics influenced diversification decisions differently in the different countries. For example, the proportion of unearned income significantly negatively affected diversification decisions in the Czech Republic and Poland, but not in Hungary. An exception to this heterogeneity, however, was level of education, where a higher level of education positively affected the probability of diversification in all three countries.

Focusing on the goals underlying decisions to diversify, Barbieri and Mahoney (2009) concluded that reduction of uncertainty and risk, followed by growth and market services, and enhancement of financial conditions were the most important goals motivating diversification decisions among farmers and ranchers in Texas. Farm and farmer characteristics underlying these goals, and thus also affecting decisions to diversify were the number of generations in the farm, household gross income, distance to urban areas and the number of full time employees.

While Barbieri and Mahoney (2009) do not make the differentiation between diversification for reasons of opportunity-pull versus necessitypush (Brockhaus 1980), the goals that they identify include both proactive responses to a detected prospect and reactive responses to unsatisfactory conditions. Rantamäki-Lahtinen (2009) reports that diversification can be both necessity- and opportunity-driven, and that the availability of idle resources can affect the direction of new activities. Firms with more agriculturally related diversification often exploited unused physical resources, whereas firms with more non-agriculturally related diversification made more use of the firm's competence resources.

In contrast to these more general studies of diversification, Sharpley and Vass (2006) and Nilsson (2002) both investigated specifically diversification through agricultural tourism in greater detail. Apart from the need or desire of extra income being a major driving force for establishing an agricultural tourism enterprise in north-eastern England, Sharpley and Vass (2006) found that the perceived benefits from working at home were also important motivating factors. Nilsson (2002) found that gender of the main entrepreneur plays a central role in development of agricultural tourism ventures, where the vast majority of the studied ventures had women in central positions. These studies show that there is reason to consider the type of venture when analyzing factors that influence diversification decisions.

Despite the range and contributions of the above sampling of the literature, there are two recurring deficiencies in most of the existing research on farm diversification. First, little attention has been paid to understanding diversification as one of multiple paths for business development. A farm that dedicated resources to a diversified activity will then not have those resources available for alternative uses. Second, the literature shows an inconsistent, often unclear distinction between the farm business, farm family income, and the farm manager, often mixing business diversification and a farmer's puriactivity. While it is well established that these three levels are intimately interconnected (Gasson et al. 1988), a distinct focus on the level of the farm business is necessary to advance understanding of farm business development.

\section{Hypotheses about factors associated with diversification and specialization}

The interest in this study lies in exploring how fundamental firm characteristics, including business structure, financial conditions, and demographic characteristics are associated with the degree of exhibited specialization in single farm enterprise, diversification within agriculture and diversification outside conventional agriculture of the farm businesses. It is assumed that farmers have economic motives in the management of their farm businesses; hence, that they aim to generate at least a satisfactory income from their farm activities and, all else being 


\section{Hansson, H. et al. The diversification and specialization of farm businesses}

equal, they prefer more income to less. Furthermore, it is assumed that farmers want to make good use of their existing farm resources, such as available labor, farm buildings and equipment, in generating income. These assumptions are well in line with findings of Alsos et al. (2003) who found that motivations behind farmers' decisions to diversify their farms included a desire to stay at the farm, for which a profitable farm would be a long-term condition, and to make use of existing resources. These assumptions are also well in line with findings of Barbieri and Mahoney (2009) who concluded that the generation of income and enhanced financial conditions were among the most important goals in farm diversifica- tion. These assumptions also support a rationale for specialization, where the focused use of resources can lead to gains from economies of scale and other competitive advantages (Porter, 1985).

This underlying view of the management behavior in farm firms together with the given dataset provides a basis for formulating a set of hypotheses that propose the influence of specific factors of business structure, financial conditions and demographic characteristics on firms' specialization and diversification within- and outside agriculture. The specific factors that are identified in the hypotheses in Table 1 are all aspects that define existing preconditions of a farm and thus, under the assumption

Table 1. Hypotheses $(\mathrm{H})$ of business structure, financial and demographic factors affecting farm business diversification and specialization.

Supporting references

Business structure

$\mathrm{H}: \mathrm{B} 1$ Previous specialization and diversification will influence the extent of future specialization and diversification, as strategic development tends to be path-dependent.

H:B2 The presence of employees will be associated with specialization, as employees are typically hired for specialized skills.

H:B3 Farms with significant seasonal variation in labor needs, or with production that is not intensive-labor, will become more diversified, as they are apt to have unused resources.

H:B4 Larger farms, given the proportionally higher value of unused resources, are more likely to diversify their production, as the lost value from unexploited opportunity will be greater.

H:B5 Incorporated companies will be more diversified in ventures outside traditional agricultural production, as the potential losses from failure in new ventures will be limited.

Mugera and Bitsch 2005

Turner et al. 2003, McNally 2001; Ilbery 1991

Mishra et al. 2004, McNally 2001; Ilbery 1991

McNally 2001, Cressy and Olofsson 1997

Financial structure

$\mathrm{H}: \mathrm{F} 1$ Weaker liquidity ratios will increase in the degree of diversification, as farmers search for alternative sources of farm income.

H:F2 Stronger solidity and return on assets will encourage increased specialization, as farmers reinvest in a profitable enterprise.

H:F3 Income from forestry in a preceding period will be positively associated with diversification, especially outside agriculture, as such internal capital can reduce risk exposure in new venture investments.

Demographic characteristics

H:D1 Diversification into value-added activities is positively associated with women, whereas diversification into new market activities is positively associated with men.

H:D2 Farms managed by older farmers will be more specialized or diversified withMcNally 2001 in conventional agriculture, whereas farms managed by younger farmers will be more diversified into enterprises outside of conventional agriculture.

H:D3 Farms in areas with higher production costs are more likely to develop diversified enterprises outside of conventional agriculture.

McNally 2001

Porter 1985

Cressy and Olofsson 1997

Turner et al. 2003 
Vol. 19(2010): 269-283.

of rational behavior, create a context for strategic decisions.

\section{The study data}

This study is based on a dataset compiled by Statistics Sweden called the Agricultural Economics Survey. The annual survey collects data from a panel of about 800-900 Swedish farm businesses with a size of at least 8 European Size Units $\left(E^{2} U^{1}\right)$, and queries on income statements and balance sheets, labor, land holdings, farm equipment, animals and inventories. Stratified sampling of the approximately 30000 qualifying farms is used to ensure good representation of geographic location, production, and size. The smaller farms that are excluded are estimated to provide less than 800 standardized hours of labor, and therein the dataset is assumed to be representative of Swedish farms in general (excluding very small holdings, which are arguably not true commercial businesses). The dataset uses a rotating panel, where a fraction of the sample is replaced each year.

The Agricultural Economics Survey database is maintained primarily for Sweden's participation in the European data network, Farm Accounting Data Network (FADN), which collects standardized farm accounting data from the member states to support EU policy and research. The Swedish dataset has limited missing values and good consistency between years. While the response rate of entering firms is only about 50 percent, responses in following years are good, and a non-response analysis has indicated little bias in the data (Jansson, 2008).

The minimum 8 ESU limit means that slightly over half of all registered farms in Sweden are not included in the survey population. While the excluded farms are likely homes valued by their occupants and contribute to rural life-style and community, they are estimated to require less than 800 standardized hours of labor, suggesting that the owner-managers of these small holdings are more dependent on off-farm income than on their farm business' commercial success. Lagerkvist et al. (2007) found that reliance on off-farm income affects the financial management of farm businesses, suggesting there is reason to consider part-time farm businesses separately from the more commercially reliant farms in the survey population. As the focus of the current study is on the strategic development of farm businesses, and not farm family households nor rural communities, the size limit is a desirable restriction of the total population.

\section{Working definitions}

The degree of specialization is defined by the share of total farm revenue coming from the main farm enterprise. Diversification is defined by activities in addition to the main enterprise that produce farm income, and can be venture within agriculture, ventures based on new markets for existing farm resources, or ventures based on value-added farm products and services, as described above.

The degree of diversification is measured by the share of total farm revenue coming from each of the diversification types. Thus, diversification within agriculture includes all revenue from traditional agricultural production, apart from the main enterprise. Diversification based on new markets for existing farm resources, includes activities such as contract work and renting out of farm buildings and fixed equipment, and diversification based on added-value farm products, includes activities such as, food processing, direct marketing produce and agricultural tourism.

\footnotetext{
${ }^{1} \mathrm{ESU}$ is based on standardized gross margins. $1 \mathrm{ESU}=1200$ euro. $1 \mathrm{ESU}$ corresponds to approximately 1.3 hectares or 1 cow
} 


\section{Results and discussion}

\section{The development of diversification and specialization $2000-2007$}

Table 2 shows the development of diversification and specialization $2000-2007$ in the sampled farms. The figures in Table 2 show that the degree of specialization is fairly consistent, with about three-quarters of total revenue coming from the main farm enterprise. However, the slight drop between 76.5 percent in 2000 and 75.4 percent in 2007 hides much of the stronger negative trend that can be clearly seen during 2000 - 2006. In light of the significant crop price increases in 2007, it can be concluded that production on farms is becoming less specialized, though market conditions at the end of the studied period counteracted a more significant restructuring of farm income.

Turning to the diversified activities, Table 2 shows that the majority of farms have diversified agricultural production, with 72 percent of farms reporting income from multiple agricultural ventures in 2000 , increasing to 74 percent in 2007 . The share of total revenue obtained from these ventures has been quite steady during the studied period, fluctuating for firms with such activities not more than one percentage point around the average of 16.5 percent.

Regarding diversification outside of conventional agriculture, Table 2 shows that there has been a more substantial increase in the number of farms reporting income from both new market ventures and added-value ventures, with new market ventures increasing from 68 percent to 75 percent, and added-value ventures increasing from none in 2000 to 5 percent of firms in 2007. While there are no grounds for suggesting causality, this change is well in line with public policy goals.

The role that diversification outside conventional agriculture is playing in farms' total revenue is more mixed. On the one hand, diversification into new market ventures fairly well follows the inverse of the pattern seen in specialization, with a gradual increase from 12.3 percent of revenues in 2000 to a top of 15.2 percent in 2006 , followed by

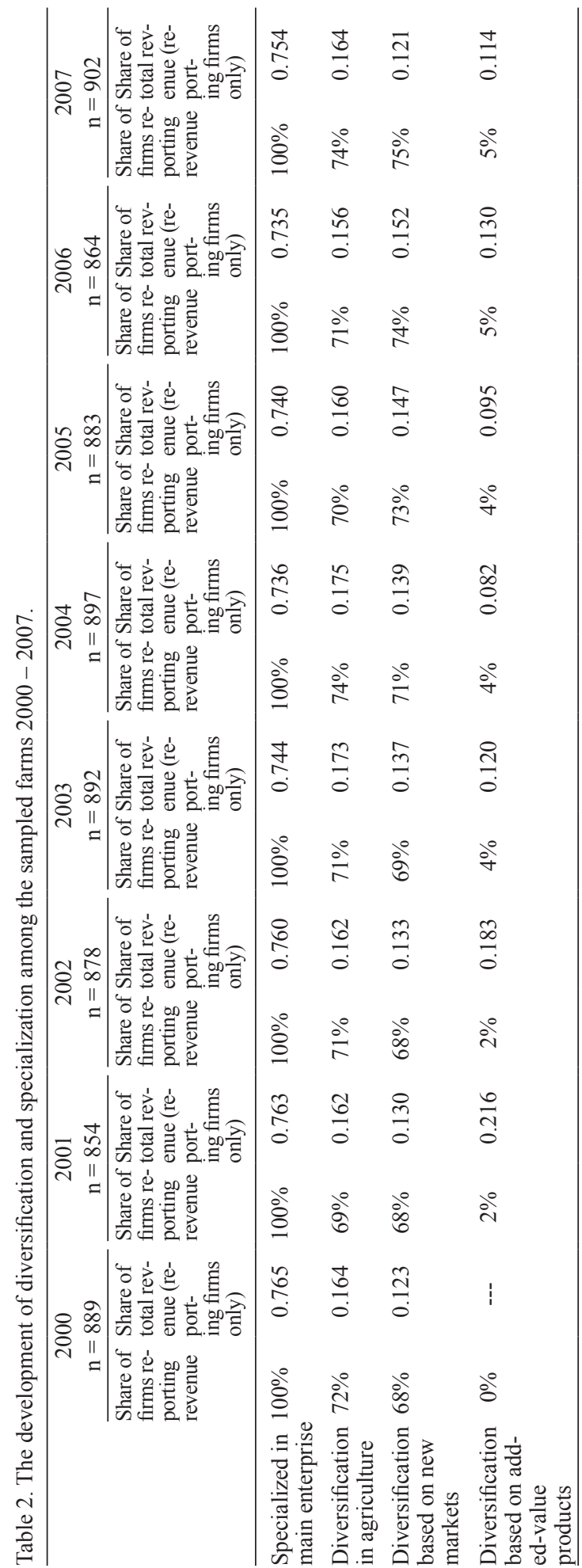


Vol. 19(2010): 269-283.

a significant drop to 12.1 percent in 2007. Again, the crop price increases in 2007 may explain much of the fall. On the other hand, the pattern of change in share of revenue from diversification based on added-value products is much more erratic, beginning with no revenues reported in 2000 , followed by the top share of revenue already in 2001 of 21.6 percent, ending in 2007 at 11.4 percent.

While perhaps 2 percent of farms generating 20 percent of their income from diversified added-value enterprises is noteworthy for that small group, for farm businesses in general the average fraction of total revenue obtained from diversification activities during the studied period is fairly small, which is much in line with earlier findings, such as McNally (2001). In particular, the average fraction of total farm revenue originating from diversification activities involving value-adding for all farms in the study never exceeds 0.6 percent, suggesting that such diversification, while perhaps significant for a single business, has only marginal effects on total farm revenues in general. On the other hand diversification into new markets contributed to at the most 11.3 percent of total revenues in the whole group, suggesting that this type of diversification outside conventional agriculture may be of more significance to the farmers.

\section{Influence of factors associated with diversification and specialization}

Moving to the second part of the study, hypotheses of the influence of factors associated with extent of specialization and diversification that have been outlined above have been tested in regression analyses of the dataset. To capture causal dependency, values for the variables measuring business structure and financial conditions were taken from the year preceding an observed diversification or specialization measurement, meaning that a sequence of two consecutive years of data for a farm are needed for a usable observation. In addition to the variables identified in the hypotheses, a variable accounting for the time trend is also included in the analyses. After removal of observations with missing values created by the rotating panel, the total number of observations in the regression analyses is 6049 . Because the dependent variables are censored, in the case of the extent of specialization at 1 and in the cases of diversification at 0 , the Tobit model was used. The Tobit model is defined as follows in the case where the censoring occurs at 1 :

$$
\begin{aligned}
& y_{i}^{*}=\sum_{i} \beta \quad x_{i}+\varepsilon_{i}, \quad i=1,2, \ldots . n, \\
& y_{i}=1 \quad \text { if } \quad y_{i}^{*} \geq 1 \\
& y_{i}=y_{i}^{*} \quad \text { if } \quad y_{i}^{*}<1
\end{aligned}
$$

where $\varepsilon_{i} \sim N\left(0, \sigma^{2}\right)$ and the $\beta: s$ are the parameters for the explanatory variables. In the case where the censoring occurs at 0 , the Tobit model is defined in the following way:

$$
\begin{aligned}
& y_{i}^{*}=\sum_{i} \beta \quad x_{i}+\varepsilon_{i}, \quad i=1,2, \ldots . n, \\
& y_{i}=0 \quad \text { if } \quad y_{i}^{*} \leq 0 \\
& y_{i}=y_{i}^{*} \quad \text { if } \quad y_{i}^{*}>0
\end{aligned}
$$

The regression results are presented in Table 3, along with notes on whether or not the hypotheses are accepted.

\section{Business structure}

Results clearly show the influence of business structure on firms' specialization and diversification, where it can be seen that the degree of specialization and diversification in a previous year positively affects the degree of specialization and diversification in a following year, as expected, giving clear support to hypothesis $\mathrm{H}: \mathrm{B} 1$. This shows that farm strategies tend to follow a trajectory, where farms that are more specialized tend to continue to be so in the future and farms that have diversified in a particular way tend to continue with that diversification in the future. This finding is not surprising, as both specialization and diversification require long-term investments and process development that have a lock-in effect.

It is also interesting to note the cross-effects between the considered farm strategies. For instance, the degree of diversification in new market activities in a preceding year has a significant and 
Hansson, H. et al. The diversification and specialization of farm businesses

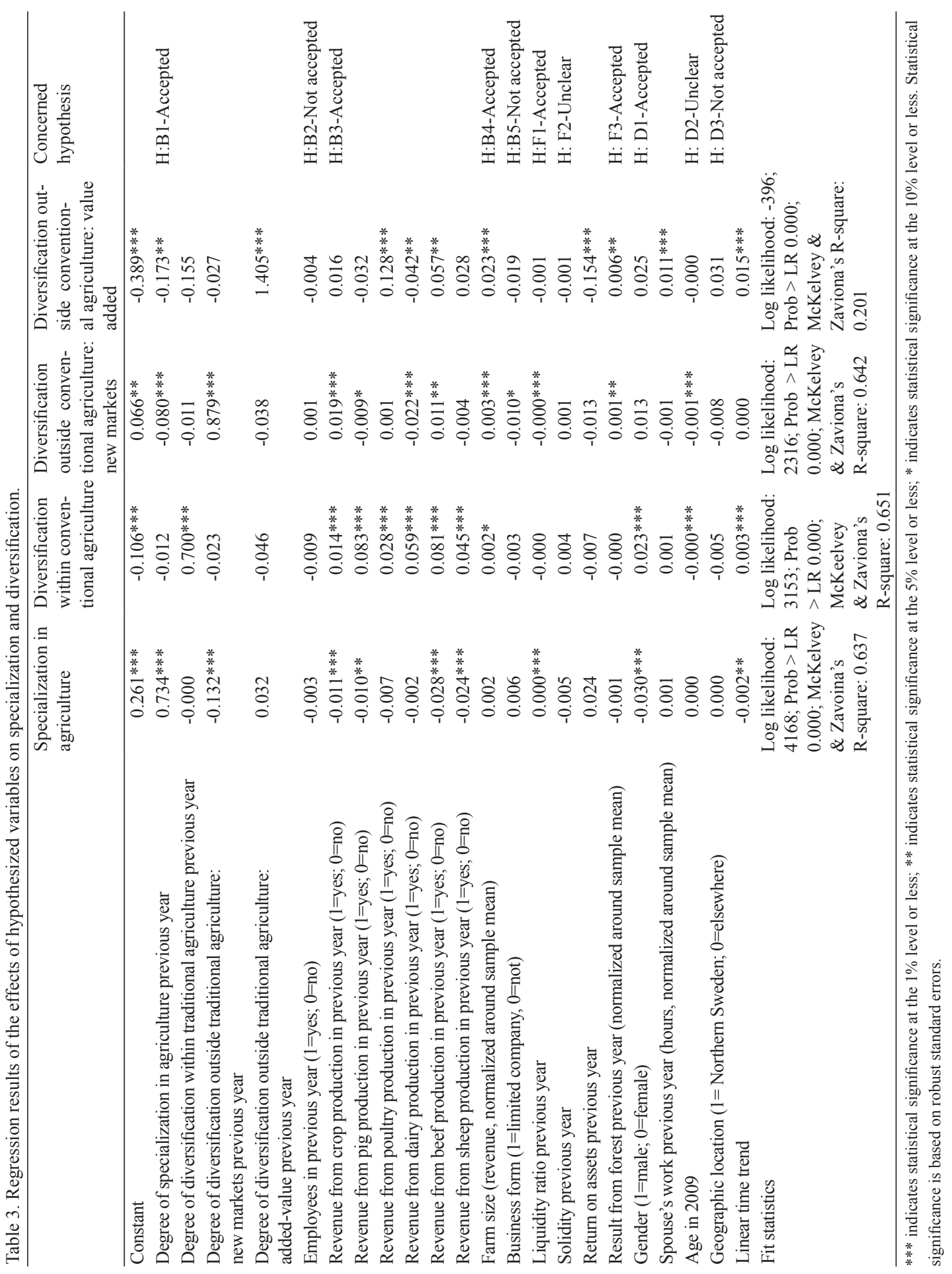


Vol. 19(2010): 269-283.

negative impact on specialization in agriculture in a following year. Moreover the degree of specialization in a preceding year has a significant negative impact on both types of diversification outside conventional agriculture. This suggests that farms that develop diversified activities related to new markets and/or added-value products have made a strategic decision to move away from traditional farming. The cross effects hence suggest that at some point in time farms make a strategic choice in the direction of their development; choosing either a strategy that is centered on conventional farming, where specialization in a single enterprise will play the leading role, perhaps supported with some secondary diversified agricultural activities, or a strategy that moves away from conventional farming, where the firm's resources are redirected or further developed to generate income in new ways.

Results further show that the presence of employees at the farms does not significantly influence firms' specialization or diversification strategies, which speaks against hypothesis $\mathrm{H}: \mathrm{B} 2$. It may be that the presence of employees neither contributes to nor deters diversification per se, but rather is an effect of the size and work load at the farm. Alternatively, though the study data did not enable an analysis of the use of employee labor in specialized versus diversified ventures within a firm, it is possible that the presence of employees can support firm development by both facilitating increased specialization and/or by providing labor for new activities, and that these two opposing stimulus hide the effects of one another in the analysis.

Results show the influence of different types of farm production on exhibited specialization and diversification. In Table 3 it can be seen that more specialized farms are significantly less likely to obtain revenue from crop, pig, beef and sheep production. Furthermore, the extent of diversification within conventional agriculture can be seen to be positively influenced by crop, pig, poultry, dairy, beef and sheep production. Results also show that dairy production, which can be considered as labor intensive livestock production, has a significant negative influence on both types of diversification outside traditional agriculture. Similarly, pig production has a significant negative impact on new market activities. In contrast, farm production which is more seasonal (e.g. crop production) or less labor intensive (e.g. beef production), show a positive association with diversification outside conventional agriculture. These results support hypothesis $\mathrm{H}: \mathrm{B} 3$, and suggest that the availability and use of labor is playing an important role in the formulation of development strategies. These results are in line with findings of McNally (2001), who reported similar findings for diversification choices of farmers in England and Wales, as well as with Ilbery (1991) who found that farms with extensive livestock production are the more diversified. This evidence suggests that there may be reason to target policy encouraging farm diversification outside agriculture towards crop farms or farms with less labor intensive livestock production.

In support of hypothesis $\mathrm{H}: \mathrm{B} 4$, the results show that a larger farm size had a significant impact on the degree of diversification outside traditional agriculture. One can also note, however, that larger farms show a greater degree of diversification within conventional agriculture. These results are in line with findings of McNally (2001), who reported that the probability of being involved in hirework or renting out of farm buildings is lower in smaller farms. The results are also in line with findings of Ilbery (1991) who found that farms with alternative enterprises tend to be larger than the average farms. The results are reasonable and expected, as larger farms are likely to have more valuable idle resources that can generate income if put to use, and thus their degree of diversification should be larger.

Contrary to what was expected in hypothesis $\mathrm{H}: \mathrm{B} 5$, business form, measured by whether the farm is an incorporated company or not, is negatively associated with the extent of diversification related to new markets, and is otherwise not significantly associated with the studied development alternatives. These findings contradict findings by McNally (2001), which may reflect cultural differences in business between England, Wales and Sweden. A possible explanation of these results is that once farmers have incorporated one company, they have the knowledge to set up additional limited corporations, and consequently may choose 
Hansson, H. et al. The diversification and specialization of farm businesses

to operate new ventures in separate companies. Though such portfolio behavior has been identified in general entrepreneurship literature (e.g Westhead and Wright 1999), starting multiple businesses as an alternative of farm business diversification is an interesting issue to be further explored.

\section{Financial conditions}

Regarding the financial conditions of the farm, results show that the liquidity ratio in a preceding year is positively associated with a farm's degree of specialization in the following year, whereas, in accordance with hypothesis $\mathrm{H}: \mathrm{F} 1$, it is negatively associated with the degree of diversification in new market enterprises. The return on assets in a preceding year is negatively associated with the degree of diversification though added-value enterprises. The results involving liquidity ratio and return on assets suggest that the degree of specialization increases when financial conditions are more favorable, whereas the degree of diversification increases when financial conditions are less favorable, as expected. Similar conclusions were made by McNally (2001), suggesting that diversification is triggered by a need to improve financial conditions rather than strong financial conditions stimulating diversification: Using Brockhaus' (1980) terminology, one might say that firms are initially pushed into diversification by the unfavorable economic conditions, rather than pulled by opportunity. The influence of the liquidity ratio on the degree of specialization supports this reasoning, where farms with more favorable conditions focus on increasing what they are already doing rather than seeking new business strategies.

Interestingly, the solidity previous year has no statistically significant influence on any of the considered strategies. In combination with the results on liquidity and return on assets, this suggests that it is the possibilities of the farms to generate income and cash flows that maters, not how the assets are financed. In support of hypothesis H:F3, results show that economic returns from forestry in a previous year is positively associated with both types of diversification outside traditional agriculture, indicating that farmers may be funding diversification with internally generated resources. If in fact so, this finding may reflect a control aversion
(Cressy and Olofsson, 1997), where firms are reluctant to diversify if it infringes upon their independence. This is an interesting issue for further research.

\section{Demographic conditions}

Table 3 reveals a number of significant effects of demographic conditions on the degree of firms' specialization and diversification. Surprisingly, businesses headed by women are found to have a higher degree of specialization, suggesting a more concentrated business strategy. At the same time, male gender is positively associated with a higher degree of diversification within agriculture, suggesting that men are more apt to look within conventional agricultural production for supplementary income. While diversification into activities outside conventional agriculture does not appear to have a gender biased based on the gender of the main farm operator, there is a positive association between spouse's labor in the firm and value-added diversification. With the vast majority of main farm operators being men, this suggests that women are playing a significant role in diversification into value-added enterprises, giving partial support to hypothesis H:D1. These results confirm the suggestions by Nilsson (2002), who concluded that gender is of central importance for diversification into agricultural tourism, but particularly in light of the contrasting finding of greater specialization in women-headed farms, the impact of gender on farm business development is a question that merits further research.

The age of the farm operator also appears to affect farms' diversification. The results show a negative association with the extent of diversification within agriculture and with diversification related to new markets. This indicates that younger operators are more apt to include revenues from any of the studied diversified activities in their total farm income, thus supporting hypothesis H:D2. A similar impact of the age of the farm operator on the probability of being engaged in contract work (which involves finding new markets for existing resources) was found by McNally (2001). 
Vol. 19(2010): 269-283.

\section{Trends over time}

A linear time trend variable was included in the analysis as a control variable, and can be seen to have a significant effect in all cases except for the degree of diversification based on new markets. Interestingly all coefficients related to diversification are positive, suggesting that the farmers are becoming more diversified over time, whereas the coefficient associated with the extent of specialization is negative, indicating a decrease in specialization over time. These trends are consistent with evidence from the descriptive statistics presented above.

\section{Conclusions}

The aim in this study has been two-fold: First, there has been an interest in tracing the development of commercial farm businesses in Sweden with regard to their degree of specialization in single farm enterprises, their degree of diversification within conventional agriculture and their degree of diversification outside conventional agriculture over the period 2000 to 2007 . Second, there has been an interest in exploring the impact of business structure, financial conditions, and demographic conditions on the degree of specialization and diversification, both within and outside of traditional agricultural production.

With respect to the first aim, clear evidence has been found of a trend towards increasing diversification into activities outside conventional agricultural production among Swedish farms. Results thus indicate that farm business development during the observed period has been in line with rural development policy goals with many farms having diversified revenues. At the same time, however, it should be noted that the observed diversification activities play on average only a minor role in total farm revenue, particularly with regard to valueadded activities, indicating that most farms remain strongly dependent on their main farm enterprise.

Regarding the second aim, evidence has been found of significant effects on firms' specialization and diversification in all three of the studied cat- egories, business structure, financial conditions and demographic conditions: While previously morespecialized farms and more-diversified farms tend to follow their respective trajectories in subsequent development, factors such as farm size and type of production appear to influence choices of specialization and different types of diversification. There is evidence that farms seek to exploit their available resources, such as the greater tendency toward diversification into non-farming enterprises by farms with significant variation in labor needs, such as crop farms and certain types of livestock production.

It is also notable that farms' access to internal sources of financing, such as return from forestry, have a significantly positive impact on the extent of both types of diversification outside conventional agriculture. While on the one hand this may further expression of the interest in exploiting firm resources, it may also indicate that farm diversification is tempered by control aversion (Cressy and Olofsson, 1997), where the use of existing internal resources is preferred.

Results also show that farms experiencing favorable financial conditions, measured in terms of higher liquidity ratio, tend to increase their specialization in following years. The opposite was also generally the case, where less favorable financial conditions, i.e. lower liquidity and lower returns on assets, were associated with diversification into activities outside conventional agriculture in following years. On the one hand, this may reflect an economic rationality, where successful enterprise stimulates further investments. However, the results also give reason to question whether diversification is an entrepreneurial act stimulated by the pull of a market opportunity (Brockhaus, 1980), or rather a defensive response to the push of unsatisfactory finances.

When comparing the estimated equations related to diversification outside conventional agriculture, it is apparent that the two types of diversification activities are not always affected the same way by the same variables. It is not surprising that diversification activities based on generating new income from existing farm resources - such as performing contract field work for neighbors or 


\section{Hansson, H. et al. The diversification and specialization of farm businesses}

renting out an unused building - are marked by different conditions than diversification activities that require the acquisition and/or development of new resources - such as building a dairy for cheese-making or developing a bed-and-breakfast. Diversification through new marketing of existing farm resources is more likely in firms with main enterprise using adaptable resources, such as crop production versus poultry production. Diversification through new value-added products and services appears to be more dependent upon the active participation of a partner, but also is more common in firms facing lower returns.

It is important to recall that these conclusions are based on a study of commercial farm businesses greater than $8 \mathrm{ESU}$, and therein should not be assumed to be valid in smaller part-time farms. The evidence presented suggests that strategic development in commercial farms is moderated by a degree of risk aversion. Smaller part-time farms may have greater opportunity to be subsidize by the farmers' pluriactivity, and therein face a different risk situation.

This study shows a clear need for further study of commercial farm business development. There is evidence that firms that are becoming more specialized differ in a number of ways from farms that are diversifying. Furthermore, there are indications of distinct differences between firms that diversify by finding new markets for their existing products and unused resources, and firms that diversify by developing new value-added products and services. If these differences are more fully understood, they can be taken into consideration for more effective design of agricultural policy and farm development advice.

Acknowledgement. We are grateful to the Editors and three anonymous Reviewers for valuable comments. This study was financed by The Swedish Research Council for Environment, Agricultural Sciences and Spatial Planning, Formas, which is gratefully acknowledged.

\section{References}

Alsos G. \& Carter S. 2006. Multiple business ownership in the Norwegian farm sector: Resource transfer and performance consequences. Journal of Rural Studies 22: 313-322.

Alsos, G., Ljunggren, E. \& Pettersen, L. 2003. Farm-based entrepreneurs: What triggers the start-up of new business activities? Journal of Small Business and Enterprise Development 10: 435-443.

Barbieri, C. \& Mahoney, E. 2009. Why is diversification an attractive farm adjustment strategy? Insights from Texas farmers and ranchers. Journal of Rural Studies 25: 58-66.

Brockhaus, R. 1980. The effect of job dissatisfaction on the decision to start a business. Journal of Small Business Management 18: 37-43.

Brümmer, B. 2001. Estimating confidence intervals for technical efficiency: the case of private farms in Slovenia. European Review of Agricultural Economics 28: 285-306.

Carter, S. 1999. Multiple business ownership in the farm sector: assessing the enterprise and employment contributions of farmers in Cambridgeshire. Journal of Rural Studies 15: 417-429.

Chaplin, H., Davidova, S. \& Gorton, M. 2004. Agricultural adjustment and the diversification of farm households and corporate farms in Central Europe. Journal of Rural Studies 20: 61-77.

Cressy, R. \& Olofsson, C. 1997. The Financial Conditions for SMEs - a Swedish case. "Financing SMEs", in Small Business Economics, 9: 179-194

Davidsson, P., Lindmark, L. \& Olofsson, C. 1999. SMEs and job creation during a recession and recovery. In Z. Acs, B. Carlsson and C. Karlsson (eds.): Entrepreneurship, small and medium-sized enterprises and the macro economy, Cambridge University Press, Cambridge. p. 286-309.

Eisenhardt, K. \& Martin, J. 2000. Dynamic capabilities: What are they? Strategic Management Journal 21: 1105-21.

Gasson, R. Crow, G. Errington, A. Hutson, J. Marsden, T. \& Winter, D. 1988. The farm as a family business: A review. Journal of Agricultural Economics 39: 1-41.

Hadley, D. 2006. Patterns in technical efficiency and technical change at the farm-level in England and Wales, 1982-2002. Journal of Agricultural Economics 57: 81100.

Hansson, H. 2007. Strategy factors as drivers and restraints on dairy farm performance: Evidence from Sweden. Agricultural Systems 94: 726-737.

Heady E. 1952. Diversification in resource allocation and minimization of income variability. Journal of Farm Economics 34: 482-496 


\section{AGRICULTURAL AND FOOD SCIENCE}

Vol. 19(2010): 269-283.

Ilbery, B. W. 1991. Farm Diversification as an adjustment strategy on the urban fringe of the West Midlands. Journal of Rural Studies 7: 207-218.

Jansson, K. (ed.) 2008. Jordbruksekonomiska undersökningen 2006, korrigerad 2008-03-13: Slutlig statistik (The 2006 Farm Economic Survey), report JO 40 SM 0801. Statistiska meddelanden. Statistics Sweden and The Swedish Board of Agriculture, Jönköping. 41 p.

Johnson S. 1967. Reexamination of the farm diversification problem. Journal of Farm Economics 49: 610-621

Lagerkvist, C J., Larsén, K. \& Olson, K. D., 2007. Offfarm Income and Farm Capital Accumulation: A FarmLevel Analysis. Agricultural Finance Review. Fall 2007: 243-257.

MacDonald, J,M., O'Donoghue, E.J, McBride, W.D., Nehring, R.F., Sandretto, C.L. \& Mosheim, R. 2007. Profits, Costs, and the Changing Structure of Dairy Farming. Economic Research report no 47. USDA Economic Research Service, Washington D.C. 41 p.

McNally, S. 2001. Farm diversification in England and Wales - what can we learn from the farm business survey? Journal of Rural Studies 17: 247-257.

Mugera, A. \& V. Bitsch. 2005. Managing labor on dairy farms: A resource-based persoective with evidence from case studies. International Food and Agribusiness Management Review 8: 79-98.

Mishra, A. El-Osta, H. \& Sandretto, C. 2004. Factors affecting farm enterprise diversification. Agricultural Finance Review 64: 151-166

Nilsson, J., Petersson, M., \& Pettersson, L. 2009. Företagandet på landsbygden - Stad eller land, gör det någon skillnad? (Business in rural communities - City or countryside, does it make any difference?), SJV rapport 2009:2. Swedish Board of Agriculture, Jönköping.

Nilsson, P. 2002. Staying on Farms. An Ideological Background. Annals of Tourism Research 29: 7-24.
Porter, M. 1985. Competitive advantages - Creating and sustaining superior performance. Free Press: New York. 557 p.

Rantamäki-Lahtinen, L. 2009. The success of the diversified farm - Resource-based view. Agricultural and Food Science 18, supplement 1, pp. 1-134. (PhD dissertation).

Robson, Paul J. A., C. Gallagher, \& M. Daly. 1993. Diversification strategy and practice in small firms. Internation Small Business Journal 11: 37-53.

Sharpley, R. \& Vass, A. 2006. Tourism, farming and diversification: An attitudinal study. Tourism Management 27: $1040-1052$.

Slee, B. 1987. Alternative Farm Enterprises, Farming press Ltd., Wiltshire. 210 p.

Statistics Sweden. 2002. Jordbruksstatistisk årsbok 2002. Statistics Sweden, Örebro.

Statistics Sweden. 2006. Jordbruksstatistisk årsbok 2006. Statistics Sweden, Örebro.

Statistics Sweden. 2008. Jordbruksstatistisk årsbok 2008. Statistics Sweden, Örebro.

Sumner D. \& Wolf C. 2002. Diversification, vertical integration, and the regional pattern of dairy farm size. Review of Agricultural Economics 24: 442-457

Tauer, L. \& Mishra, A. 2006. Dairy Farm Cost Efficiency. Journal of Dairy Science 89: 4937-4943.

Teece, D.J., Pisano, G. \& Shuen, A. 1997. Dynamic capabilities and strategic management. Strategic Management Journal 18: 509-533.

Turner, M., Whitehead, D., Barr, D., Fogerty, M., Errington, A., Lobley, M. \& Reed M. 2003. Farm Diversification Activities: Benchmarking study 2002 - Final report to DEFRA. U. of Exeter \& U. of Plymouth. Retreived 2010-0615 from <http://www.defra.gov.uk/evidence/ economics/ foodfarm/reports/farmdiv/index.htm>.

Westhead, P. \& Wright, M. 1999. Contributions of novice, portfolio and serial founders located in rural and urban areas. Regional Studies 33: 157-173. 